\title{
"A DOMINAÇÃO" DE MAX WEBER PELOS SEUS MANUSCRITOS INACABADOS (1911-1913)
}

\author{
La domination. (2013). Max Weber. Trad. Isabelle Kalinowski.
}

Paris: La Découverte, 432 p.

Nascido há I50 anos, em Erfurt, capital da Turíngia, na Alemanha, Maximilian Karl Emil Weber pode ser lembrado por diferentes caminhos. Como um dos fundadores da Sociologia, sua figura é associada a temas específicos: suas prodigiosas análises sobre a origem do capitalismo, sua erudição aplicada à fundação de uma teoria da religião; suas reflexões críticas sobre o método nas ciências sociais, sem o estabelecimento de rígidas fronteiras disciplinares; ou, ainda, suas teses sobre o poder e as formas de dominação.

Sobre este último tema, a editora francesa La Découverte, nos quadros de sua "Collection Politique et Sociétés" dirigida pelo sociólogo francês Yves Sintomer, publicou, em dezembro último, os manuscritos produzi- dos pelo autor entre igi I e I9I3, numa edição crítica empreendida a partir da tradução da publicação, na Alemanha, em 2005, do primeiro volume de Max Weber Gesamtausgabe, intitulado Wirtschaft und Gesellschaft. Die Wirtschaft und die gesellchaftlichen Ordnungen und Mächte. Nachla $\beta$ do tomo 4: Herrschaft.

Sintomer, também autor de uma longa introdução à edição francesa, justifica a importância da publicação sob o argumento de que a influência da Sociologia Política de Max Weber em escala internacional não corresponde à forma fragmentada como seus temas foram traduzidos em partes que compuseram os exemplares de Wirtschaft und Gesellschaft (Economia e sociedade), reunidos na seção Soziologie der Herrschaft (Sociologia 
da dominação), combinadas a alguns textos isolados para reforçar uma unidade, autonomia, ou sistematicidade, que não existiam nos originais inacabados de Weber, publicados postumamente.

O trabalho atual apresenta conceitos e categorias definidos de modo mais preciso, por vezes a partir de noções complementares, como a de "disciplina", que precede a definição do conceito de dominação. Seus desdobramentos podem evidenciar algumas imprecisões em traduções clássicas de Wirtschaft und Gesellschaft, como o fez Talcott Parsons, por exemplo, ao traduzir "Herrschaft" por "authority", na edição para a língua inglesa (Sintomer, 20I3: 2I).

Ao redigir estes manuscritos inacabados, Weber forjou noções fundamentais para a constituição de uma sociologia política. Sua "erudição" e "inventividade" nas construções conceituais, herdada em certa medida do neokantismo (Ringer, 2004), aparecem nos estudos sobre os três modos de dominação legítima, na passagem da dominação dos notáveis para a dos partidos de massa, na oposição status do grupo (Stand)/classe (Klasse), nas análises sobre o patrimonialismo, sobre a hierocracia ou sobre a dominação carismática e suas funções correlatas.

A publicação, além de duas curtas notas editoriais sobre as traduções francesas de Wirtschaft und Gesellschaft e La domination e a introdução de Yves Sintomer, está dividida em seis partes, da mesma forma que os originais deixados por Weber. Tais divi- sões apresentam discussões que vão de uma síntese sobre o que ele entende por dominação naquele momento, passando pelas análises das dominações burocrática, patrimonial, feudal e carismática; deixando para uma última seção a retomada de temas como religião no Ocidente, capitalismo e democracia modernos, reunidos em "O Estado e a hierocracia".

Em La domination, a dimensão simbólica da dominação, não permite que se confunda dominação e poder, conceitos relacionais, mas distintos, visto que a legitimidade aparece como um componente intrínseco à dominação. Esta última aparece como "disposição inculcada", "obediência acrítica e sem resistência”, reconhecida como válida pelas pessoas sobre as quais ela se exerce. Diz respeito à sociologia da dominação weberiana aplicada à análise da esfera política, cujo conceito central não são as relações de poder em geral, mas a própria ordem social institucionalizada. Daí sua ideia da democracia moderna como a dominação das elites fortemente legitimada pelo povo.

Compreender a dominação neste sentido amplo, para além das instituições formais ou legais, ampliou as possibilidades de compreensão das relações sociais nas sociedade modernas. Ao tomar a definição weberiana de Estado como ponto de partida, a explicação das gêneses e funções de monopolização da violência simbólica, elaborada por Pierre Bourdieu, constitui um exemplo que não nega tal afirmação. 
Em um sentido mais restrito, a singularidade da compreensão weberiana explica como vontade e intencionalidade são fundamentais para que haja dominação. Para Weber, a crença na legitimidade da "ordem" recebida tem origem nas "regras racionais instituídas", por pacto ou concessão. Daí a importância dos estudos, e compreensão, das três formas puras "típico-ideais" de dominação: a legal, a tradicional e a carismática, como dotadas de um caráter provisório, de validades heurísticas. Excluindo-se a ideia de que a dominação se estrutura pela ação de um indivíduo isolado,

A "dominação" em seu sentido mais geral, antes de reportá-la a um conteúdo concreto, é um dos elementos mais importantes da ação comum. É verdade, no entanto, que toda ação comum não apresenta a estrutura de uma dominação, embora tenha papel significativo, na maior parte das modalidades como esta última se apresenta. É o caso das comunidades linguísticas. Os decretos que elevam um dialeto ao status de língua administrativa, em uma gestão política dominante, têm um papel decisivo no desenvolvimento das comunidades literárias unificadas (pensemos na Alemanha) e, ao contrário, é muito frequente que uma diferenciação linguística seja definitivamente endossada quando uma separação política foi consumada (a Holanda contra a Alemanha). Sobretudo, a dominação exercida na "escola" transforma em estereótipo marcante e definitivo a natureza e a supremacia da língua escolar oficial (Weber, 2013: 43).

Ou seja, para Weber, é a estrutura da dominação e seu desenvolvimento que dão forma ao agir comum, orien- tando-o para um "fim/objetivo". No entanto, como declina do carisma a força revolucionária criadora da história, justamente porque compreende a política como ação de grandes homens, de um grupo reduzido de indivíduos, mulheres, camponeses e movimentos de massa não encontram ressonância em La domination.

Para Sintomer (2013: 30), tudo se passa como se Weber se identificasse com o ponto de vista dos dominantes, como se ele ignorasse as contraposições dos subalternos, as iniciativas racionais provenientes daí, como se a dominação fosse uma força sem reação, como se não tivesse um inverso. Aqui, em La domination, assim como nos estudos empreendidos desde igog sobre os "julgamentos de valor" e as ciências sociais, permanecem as fragilidades entre a tomada de uma posição axiológica e a realização de trabalhos científicos, o dilema entre a produção do conhecimento científico nas ciências sociais e as intervenções na vida pública alemã, por parte do autor.

A leitura de Sintomer, por sua vez, propõe uma crítica às perspectivas radicais que interpretam "a ciência livre de julgamentos de valor" como uma ideia mais weberiana do que o próprio Weber, pois ao fazerem isso, retiram das ciências humanas e sociais sua dimensão pública, afastam-se de uma ideia mais restrita da tese de Weber, mais coerente com aquilo que ele mesmo praticava e mais próxima do fascínio que a leitura de La domination pode criar. 
[...] podemos concordar com Weber quando ele critica fortemente a exclusão de figuras brilhantes da universidade por razões político-teóricas, na sua recusa - aos antípodas durkheimianos - de deduzir de modo imanente uma tomada de posição normativa de um julgamento de fato, ou ainda na sua construção de tipos-ideais podendo reunir em uma ótica cognitiva personagens ou acontecimentos opostos sobre o plano dos valores. [...] é possível defender que a objetividade (Sachlichkeit) das ciências sociais, se ela implica alguma articulação entre os julgamentos de valor e os de fato, não significa que os dois se confundam; ela não exclui tomadas de posições ético-políticas, mas impõe recusar a propaganda e contrabalançar a paixão do engajamento por uma confrontação - a mais rigorosa possível - com a empiria, pela construção de noções capazes de dar conta dela do modo mais completo possível, por uma atenção escrupulosa em relação à coerência e à credibilidade da explicação e pelo jogo de confrontação com a crítica no espaço público científico, mas também nas arenas híbridas (Sintomer, 2013: 31-32).

Sob esta argumentação, as ações práticas de Weber acomodam-se melhor à sua recusa dos "julgamentos de valor" (Werturteile) nas ciências sociais, assim como afasta a ideia de uma tradição intelectual "elitista" ou pretensamente "crítica". Evidentemente que não desfaz, no plano social, as diferenças existentes entre suas sucintas contribuições e as de Marx ou de Durkheim.

Em La domination, o fio condutor da análise weberiana sobre o Ocidente moderno, a partir do exame da conduta de vida dos indivíduos neste mundo - tematizando movimentos múltiplos de racionalização, afastada de qualquer unicidade ou caráter progressivo - consolida ideias já apresentadas em obras anteriores, sobretudo as dedicadas ao tema das religiões. Isto reforça seu distanciamento de Marx e Durkheim, na medida em que não existe uma explicação baseada no desenvolvimento progressivo dos modos de produção, ou outra que associe a decadência da civilização moderna à perda de seus vínculos com a fé, a comunidade ou a ordem tradicional. Os esforços estão concentrados na seguinte questão: "como explicar que o estado burocrático e o capitalismo tenham se desenvolvidos plenamente, e em conexão tão íntima, no Ocidente, e não em outros lugares e tempos, já que múltiplos processo de racionalização marcaram a história da humanidade?" (Sintomer, 2013: 34 e 35).

O Ocidente tem lugar privilegiado no método comparativo do autor, é o ponto de convergência da comparação; lugar a partir do qual o processo de racionalização do Estado e da economia são pensados. Esta parte do planeta, onde organização política e econômica se vincularam de modo tão particular, está para Weber bem situada geograficamente, trata-se da Europa e dos Estados Unidos, e é datada, pois diz respeito a uma época em que ambos estão no centro do "sistema-mundo" impondo sua superioridade econômica, técnica e militar ao resto das nações.

Neste sentido, as experiências históricas, como marca Sintomer, 
talvez não nos permitam sermos weberianos, isto é, tomar os regimes de dominação política tematizados por Weber para pensar nas potências, estabelecidas e emergentes, do século XXI. Todavia, assim como na relação entre os "julgamentos de valor" e as práticas das ciências sociais, o que importa é confrontar paixão e empiria; aqui, o que merece ser considerado e tomado como inspiração é, antes, a compreensão e utilização do tipo-ideal não como um meio, mas como recurso metodológico que construímos selecionando alguns aspectos da realidade, insistindo sobre sua coerência sistêmica, separando os elementos heterogêneos, a fim de chegar a uma categoria que se oponha, ou se combine a outras. Para compreender um caso concreto, de um modo geral, é necessário combinar vários tipos-ideais, é preciso situá-lo não num quadro, agrupando-o num conjunto, mas num "mapa conceitual", onde eles sejam os pontos cardeais. Este instrumental dos "quadros de pensamento" deve funcionar como recurso heurístico, conduzindo a pesquisa em momentos determinados, medindo as direções que tomam as evoluções de suas dinâmicas concretas.

Em La domination, a tipologia dos modos de dominação legítimas, entendidas como típicas-ideais, não permite que o real e suas realidades múltiplas sejam simplificados, muito menos que o pesquisador se perca em sua multiplicidade infinita. O que ratifica qualquer leitura do autor como "bússola" valiosa para o pesquisador, mesmo nas emaranhadas representações da dominação postas no século XXI, na "modernidade-mundo".

A publicação destes manuscritos, no ano em que se completa um século e meio do nascimento de Max Weber, reforça a importância de sua produção teórica para as Ciências Sociais e, igualmente, ratifica aquilo que já havia sido mostrado por Pierucci (2013), e ressaltado por Cohn (20I3), a respeito do conceito de "desencantamento". $\mathrm{Na}$ teoria weberiana o conceito foi construído para explicar o mundo, não para lamentá-lo. A mesma "tese forte" pode ser aplicada às análises sobre a dominação publicadas na sua forma original em La domination. 
“A DOMINAÇÃO” DE MAX WEBER PELOS SEUS MANUSCRITOS INACABADOS (I9I I - I9I3)

592

Mariana Barreto é mestre e doutora em Sociologia pela Universidade Estadual de Campinas (Unicamp), e professora adjunta I do Departamento de Ciências Sociais da Universidade Federal do Ceará (UFC). Interessa-se por temas vinculados à Sociologia da Cultura, tais como: produção e consumo culturais, formação das indústrias culturais no Brasil e trajetórias artísticas. É autora de "Majors e hegemonia no mercado fonográfico brasileiro" (2013) e "A trajetória de João do Vale e os lugares de sua produção musical no mercado fonográfico brasileiro" (2012). 


\section{REFERÊNCIAS BIBLIOGRÁFICAS}

Ianni, Octávio. (200o). Enigmas da modernidade-mundo. Rio de Janeiro: Civilização Brasileira.

Lenoir, Remi. (2012). Bourdieu avec Weber. In: Lebaron, Frédéric \& Mauger, Gérard (orgs.). Lectures de Bourdieu. Paris: Ellipses, p. 4I-59.

Pierucci, Flávio. (2013). O desencantamento do mundo. Todos os passos do conceito em Max Weber. 3. ed. São Paulo: Edusp/Ed. 34. Ringer, Fritz K. (2004). A metodologia de Max Weber. Unificação das ciências culturais e sociais. Trad. Gilson César Cardoso de Sousa. São Paulo: Edusp.

Ringer, Fritz K. (2000). O declínio dos mandarins alemães. Trad. Dinah de Abreu Azevedo. São Paulo: Edusp.

Sintomer, Yves. (2013). Introduction. In: Weber, Max. La domination. Trad. Isabelle Kalinowski. Paris: La Découverte, p. II-39. 